\title{
14-Deoxyandrographolide Isolated from Andrographis paniculata (Burm. f) Nees Growing in Bangladesh and its Antimicrobial Properties
}

\author{
Parisa Tamannur Rashid ${ }^{1}$, Muniruddin Ahmed ${ }^{1}$, Md. Mizanur Rahaman ${ }^{2}$ \\ and Md. Abdul Muhit ${ }^{1}$
}

${ }^{1}$ Department of Clinical Pharmacy and Pharmacology, University of Dhaka, Bangladesh

${ }^{2}$ Department of Microbiology, University of Dhaka, Bangladesh

(Received: October 4, 2018; Accepted: December 12, 2018; Published (web): December 10, 2018)

Andrographis paniculata (Family: Acanthaceae), usually known as Kalmegh or King of Bitters ${ }^{1}$, is a bitter annual herb commonly found in the plain lands of Bangladesh, India, Sri Lanka and West Indies. ${ }^{2}$ It is extensively used as home remedy for various diseases in Ayurvedic, Unani, Siddha as well as tribal medicines. ${ }^{3}$ The plant is beneficial to liver disorders, common cold, upper respiratory tract infection ${ }^{4-6}$ and also cools and relieves internal heat, inflammation and pain. ${ }^{7,8}$ The main bitter constituents of the plant are labdane type diterpene lactones namely andrographolide, neoandrographolide, 14-deoxy11,12-didehydroandrographolide, 14-deoxy-11-oxoandrographolide and 14-deoxyandrographolide. ${ }^{9}$ Previous reports suggested that andrographolide-type compounds possess strong antimicrobial activity against several organisms. ${ }^{10}$ The present study was designed to isolate antimicrobial compounds from the ethanolic extract of the leaves and stems of $A$. paniculata. We, herein, report the isolation of 14deoxyandrographolide and its antimicrobial activities against two clinical bacterial species collected from local diagnostic centers namely Salmonella typhi and Escherichia coli.

The leaves and stems of the plant were collected from the Medicinal Plant Garden, Faculty of Pharmacy, University of Dhaka in September, 2017 and identified as Andrographis paniculata (Family:

Correspondence to: Md. Abdul Muhit

E-mail: <muhit@du.ac.bd>; Phone: +88-01733-982854

Dhaka Univ. J. Pharm. Sci. 17(2): 265-267, 2018 (December) DOI: http://dx.doi.org/10.3329/dujps.v17i2.39185
Acanthaceae) by Professor Dr. Muniruddin Ahmed, Department of Clinical Pharmacy and Pharmacology, University of Dhaka, Bangladesh. The plant samples were air dried and crushed into coarse powder. Dried coarse powder ( $29 \mathrm{~g}$ ) was soaked in approximately $150 \mathrm{ml}$ of distilled ethanol at room temperature for 72 hours and filtered using cotton pads and finally by Whatman filter paper number 1 . The crude extract $(2.4 \mathrm{~g})$ was then obtained by evaporating the filtrate with a rotary evaporator under reduced pressure.

Ethanolic crude extract was subjected to silica gel column chromatography eluted with chloroformmethanol (99:1) with increasing polarities to yield 91 fractions of each containing 20-25 ml approximately. After meticulous observations on TLC of the column fractions, total 13 fractions (A-N) were prepared by appropriate TLC screenings. White crystals along with green color appeared from the fraction $\mathrm{G}$ ( 92.8 $\mathrm{mg}$ ). The crystals could not be purified through recrystallization procedure. Preparative thin layer chromatography (PTLC) using chloroform-methanol (95:5) afforded white crystals of 14-deoxyandrographolide with a $R_{f}$ value of 0.7 on precoated TLC plate over silica gel. The structure of the isolated compound was determined by careful analysis of its ${ }^{1} \mathrm{H}-\mathrm{NMR}$ and ${ }^{13} \mathrm{C}$-NMR spectral data acquired on a Bruker instrument at Wazed Miah Research Centre, Jahangirnagar University, Savar, Bangladesh, operating at $400 \mathrm{MHz}$ and $100 \mathrm{MHz}$, respectively.

14-Deoxyandrographolide (1). White crystals; ${ }^{1} \mathrm{H}$ NMR (400 MHz, $\mathrm{CDCl}_{3}$ ): $\delta 0.65$ and 1.25 (each 3H, 
s, H-20 and H-18), $1.85\left(12 \mathrm{H}, \mathrm{m}, 6 \mathrm{CH}_{2}\right), 3.33(1 \mathrm{H}$, $\left.\mathrm{d}, J=7.0 \mathrm{~Hz}, \mathrm{H}_{\mathrm{a}}-19\right), 3.48(1 \mathrm{H}, \mathrm{t}, J=3.5 \mathrm{~Hz}, \mathrm{H}-3)$, $4.21\left(1 \mathrm{H}, \mathrm{d}, J=7.0 \mathrm{~Hz}, \mathrm{H}_{\mathrm{b}}-19\right), 4.61\left(1 \mathrm{H}\right.$, br. s, $\mathrm{H}_{\mathrm{a}}-$ 17), $4.78(2 \mathrm{H}, \mathrm{d}, J=1.5 \mathrm{~Hz}, \mathrm{H}-15), 4.81(1 \mathrm{H}$, br. s, $\left.\mathrm{H}_{\mathrm{b}}-17\right), 7.11\left(1 \mathrm{H}\right.$, br. s, H-14); ${ }^{13} \mathrm{C}$ NMR $(100 \mathrm{MHz}$, $\left.\mathrm{CDCl}_{3}\right): \delta 174.3(\mathrm{C}-16), 146.8(\mathrm{C}-8), 144.0(\mathrm{C}-14)$, 134.7 (C-13), 107.4 (C-17), 80.6 (C-3), 70.1 (C-15), 64.2 (C-19), 56.1 (C-9), 55.3 (C-5), 42.9 (C-4), 39.1 (C-10), 38.2 (C-7), 36.9 (C-1), 28.1 (C-2), 24.6 (C12), 24.0 (C-6), 22.7 (C-18), 22.0 (C-11), 15.2 (C20).

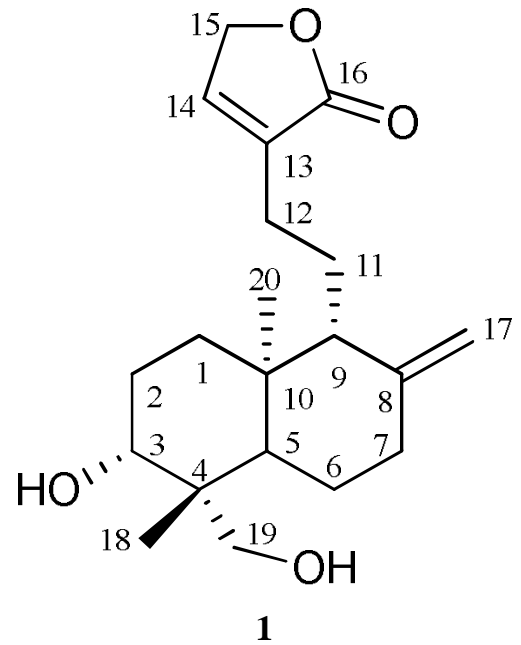

The ${ }^{1} \mathrm{H}$-NMR spectrum of the isolated compound revealed two methyl signals at $\delta 0.65$ and 1.25 , two exomethylene protons at $\delta 4.81,4.61$ as broad singlet, a $s p 2$ hybridized olefinic proton at $\delta 7.11$ and a pair of oxymethylene protons at $\delta 4.78$ as doublet with a coupling constant of $1.5 \mathrm{~Hz}$. The above data suggested an andrographolide-type skeleton which has been reported from this plant previously. ${ }^{2}$ The ${ }^{13} \mathrm{C}$-NMR spectrum $\left(100 \mathrm{MHz}, \mathrm{CDCl}_{3}\right)$ of the compound displayed 20 carbon resonances which in accordance with the ${ }^{1} \mathrm{H}$ NMR spectral data supported the presence of labdane diterpenoid. ${ }^{9}$ A downfield proton at $\delta 3.48$ appeared as triplet can be located at position of C-3. A pair of methylene protons appeared at $\delta 4.21$ and 3.33 with a coupling constant of $7 \mathrm{~Hz}$ can be assigned to the protons at $\mathrm{C}-19$. The ${ }^{13} \mathrm{C}$ signal at $\delta 174.34$ could be assigned to a lactone carbonyl group. The signals $\delta 64.18$ and 70.12 could be attributed to methylene carbons $\mathrm{C}-19$ and $\mathrm{C}-15$, respectively. The ${ }^{13} \mathrm{C}$ resonances over $\delta 100.0$ usually indicate the appearance of carbon-carbon double bonds. Therefore, the signals at $\delta 107.4,134.7,144.0$ and 146.8 could be assigned for the olefinic carbons at C-17, C-13, C-14, and C-8 positions, respectively. According to the above spectral data, the structure of the compound was deduced as 14deoxyandrographolide (1), which was confirmed by comparison of its spectral data with published value. $^{11}$

The isolated compound $\mathbf{1}$ was subjected to screening for its antimicrobial properties. The test was performed by disc-diffusion technique ${ }^{12}$ against two clinical isolates such as $S$. typhi and E. coli. collected from the blood and urine samples of the affected patients, respectively. The discs were impregnated with 20 and $50 \mu \mathrm{g}$ of the isolated compound $\mathbf{1}$ and the activity was compared with that of the positive control, ciprofloxacin. The compound 1 showed mild antimicrobial activity against E.coli. with a zone of inhibition of $8 \mathrm{~mm}$ at a concentration of $50 \mu \mathrm{g} /$ disc but it did not show any activity against S. typhi. Interestingly, more than $60 \%$ urine samples (E. coli.) collected from different patients were found to be resistant against ciprofloxacin in our study which were moderately sensitive to the isolated compound 1. Due to low amount of yield of $\mathbf{1}$, the percentage sensitivity on different patient's specimen could not be screened out. Nevertheless, it can be postulated that andrographolide derivatives could be a potential lead to open a new horizon for fighting against resistant type bacteria (E. coli.).

\section{REFERENCES}

1. Mishra, S.K., Sangwan, N.S. and Sangwan, R.S. 2007. Andrographis paniculata (Kalmegh): A review. Pharmacogn. Rev. 1, 283-289.

2. Kulyal, P., Tiwari, U.K., Sukla, A. and Gaur, A.K. 2010. Chemical constituents isolation from Andrographis paniculata. Indian J. Chem. 49B, 356-359.

3. Chopra, R.N., Nayar, S.L. and Chopra, I.C. 1956. Glossary of Indian Medicinal Plants, NISCOM, CSIR, New Delhi, India.

4. Negi, A.S., Kumar, J.K., Luqman, S., Sbanker, K., Gupta, M.M. and Kbanuja, S.P.S. 2008. Recent advances in plant hepatoprotectives: a chemical and biological profile of some important leads. Med. Res. Rev. 28, 821. 
5. Roxas, M. and Jurenka, J. 2007. Colds and influenza: A review of diagnosis and conventional, botanical and nutritional considerations. Altern. Med. Rev. 12, 25-48.

6. Kligler, B., Ulbricht, C., Basch, E., Kirkwood, C.D., Abrams, T.R., Miranda, M., Singh, K.P., Giles, M., Boon, H. And Woods, J. 2006. Andrographis paniculata for the treatment of upper respiratory infection: a systematic review by the natural standard research collaboration. Explore 2, 25-29.

7. Huang, C.J. and Wu, M.C. 2002. Differential effects of foods traditionally regarded as 'heating' and 'cooling' on prostaglandin E2 production by a macrophage cell line. $J$. Biomed. Sci. 9, 596-606.

8. Mandal, S.C., Dhara, A.K. and Maiti, B.C. 2001.Studies on psychopharmacological activity of Andrographis paniculata extract. Phytother. Res. 15, 253-256.
9. Patra, A., Mitra, A.K., Biswas, S., Gupta, C.D., Basak, A. and Barua, A.K. 1981. Carbon-13 NMR spectral studies on some labdane diterpenoids. Org. Magn. Reson. 16, 75-77.

10. Banerjee, M., Parai, D., Chattopadhyay, S. and Mukherjee, S.K. 2017. Andrographolide: antibacterial activity against common bacteria of human health concern and possible mechanism of action. Folia Microbiol. 62, 237-244.

11. Wang, J.H., Wang, Z.T., Wang, L.L., Wang, Z.J., Ma, Z., Chou, G.X., Hu, Z.B. and Li, W.K. 2014. Biotransformation of neoandrographolide by endophytic fungus from Dendrobium officinale Kimura et Migo. Asian J. Chem. 26, 3457-3460.

12. Bauer, A.W., Kirby, W.M., Sherris, J.C. and Turek, M. 1966. Antibiotic susceptibility testing by a standardized single disc method. Am. J. Clin. Pathol. 45, 493-496. 